Influência de diferentes concentrações de flúor na água
em indicadores epidemiológicos de saúde/doença bucal

Influence of different concentrations of fluoride in the water

on epidemiologic indicators of oral health/disease

Raquel Baroni deCarvalho ${ }^{1}$

Urubatan Vieira de M edeiros ${ }^{2}$

Karina Tonini dos Santos ${ }^{3}$

Antônio Carlos Pacheco Filho ${ }^{3}$

${ }^{1}$ Departamento deM edicina Social, Centro de Ciências da Saúde, Universidade Federal do Espírito Santo. Av. M arechal Camposs/n, Maruípe. 29040-100 Vitória ES.

raquel_baroni@yahoo.com.br

${ }^{2}$ Departamento de

Odontologia Preventiva e

Comunitária, Universidade

Estadual do Rio de Janeiro.

${ }^{3}$ UniversidadeEstadual

Paulista.
Abstract The scope of this study was to evaluate access to fluoride sources and oral health hygiene of 237 schoolchildren aged nine to sixteen, from three locations with different fluoride concentrations in the water. The fluoride level in the water of each area was analyzed by the selective electrode technique for the fluoride ion and the prevalence of dental caries and fluorosis were evaluated, respectively, by the DMFT and TSIF index, revealing a statistically significant difference (AN OVA; $p<0,05$ ) in the three locations: area without artificial fluoridation (DMTF $5.32 \pm$ 3.49 ) and $16 \%$ of dental fluorosis; area with artificial fluoridation of $0.8 \mathrm{ppmF}$ (DMTF $1.88 \pm$ 2.22) and $94 \%$ of dental fluorosis; area with natural fluoridation of $2.54 \mathrm{ppmF}$ (DMTF $3.96 \pm$ 2.38 ) and $100 \%$ of dental fluorosis. The findings suggest that the epidemiologic indicators of oral health/disease are influenced by the presence of fluoride in the water supply and that supervision and orientation are fundamental in the correct use of fluoridated compositions, taking advantage of the maximum benefit in the control of dental caries with minimum risk of the occurrence of dental fluorosis.

Key words Epidemiology, Oral health, Public health
Resumo 0 objetivo deste estudo foi avaliar o acesso a fontes de fluoreto e as condi ções de saúde bucal de 237 escolares de nove a dezesseis anos, de três localidades com diferentes concentrações de fluoreto na água. 0 teor de flúor na água de cada região foi analisado pela técnica do eletrodo seletivo para o íon flúor e a foi avaliada prevalência de cárie e fluorose, respectivamente, pelo índice CPOD e TSIF, apresentando diferença estatisticamente significante (AN OVA; $p<0,05$ ) nas três localidades: área sem fluoretação artificial (CPOD $5,32 \pm 3,49$ ) e $16 \%$ defluorose; área com fluoretação artificial de 0,8 ppmF (CPOD 1,88 $\pm 2,22$ ) e $94 \%$ de fluorose; área com fluoretação natural de 2,54 ppmF (CPOD 3,96 $\pm 2,38$ ) e $100 \%$ de fluorose. Os achados sugerem que os indicadores epidemiológi cos de saúde/doença bucal estudados são influenciados pela presença defluoreto na água de consumo e que a supervisão e a orientação são fundamentais na correta utilização dos compostos fluoretados, aproveitando-se o máximo benefício no controle da cárie dentária com o mínimo risco de ocorrência de fluorose.

Palavras-chave Epidemiologia, Saúde bucal, Saúde pública 
Introdução

O flúor possui eficácia cientificamente comprovada no combate e na preven ção da cárie dentária, sendo muito utilizado em grande parte do mundo, por sua adição na água de abastecimento público, ao sal, a géis ea soluções para boche cho de utilização tópica, a vernizes fluoretados, a dentifrícios e a materiais restauradores.

Entretanto, a ingestão excessiva do íon flúor pode ocasionar a fluorose dentária. Essa patologia resulta de um distúrbio ocorrido durante a formação do elemento dentário, caracterizada por uma hipomineralização do esmalte, causada pela ingestão excessiva de flúor ${ }^{1,2}$. A distribuição eseveridade dessa patologia estão principalmente relacionadas com a quantidade de flúor ingerido, com a duração da exposição, e com o estágio da amelogênese na qual houve a intoxicação ${ }^{3}$.

A prevalência da fluorose ao que tudo indica está seguindo um padrão inverso ao da doença cárie, com taxas crescentes relatadas no mundo inteiro ${ }^{4}$. A sua prevalência tem se manifestado principalmentenasformas leveemuito leve, sendo observada tanto em comunidades com água fluoretada como em comunidades que não possuem fluoretos na água ${ }^{5,6}$.

Desde década de 30, nos EUA, Dean já havia descrito inúmeros levantamentos que demonstraram a associação positiva entre a concentração de fluoretos na água potável e o predomínio e as gravidades da fluorose dentária, porém, verificou também a existência de baixa prevalência de cárie nesta mesma população?.

Muitas pesquisas no Brasil foram realizadas com o intuito de verificar o efeito do teor deflúor da água de consumo, seja ele natural ou adicionado, na prevalência de cárieefluorose, evárias delas comprovaram a relação da dosagem de flúor na água e a prevalência de fluorose dentária ${ }^{8-13}$.

Entretanto, como ressaltam Cangussu et al..$^{14}$, é importante que as pesquisas relatem os casos moderados e severos da doença, pois esses são considerados de importância para a saúde coletiva por provocar alterações estéticas e funcionais significativas, epercebidas como de relevância social para a comunidade.

Desta maneira, a deficiência de observações relativas à saúde bucal de escolares de todo 0 Brasil, especial mente aquel es residentes em localidades com diferentes situações de fluoretação da água, motivou uma busca de dados fundamentais para a melhor interpretação de possíveis fatores inerentes à forma de fluoretação e à concentração do íon flúor da água, relacionados aos indicadores epidemiológicos de saúde/doença bucal.

\section{Materiais emétodos}

Trata-se de um estudo epidemiológico descritivo, pois se preocupa em informar a distribuição deum evento na população em termos quantitativos.

Seleção da amostra

Posteriormente à aprovação no Comitê de Ética em Pesquisa, foi realizada uma seleção dos escolares, de forma sistemática, para participar da pesquisa clínica. Os critérios de inclusão consistiram em selecionar alunos das localidades escolhidas que haviam nascido e residido por toda a vida nesses respectivos locais, ou seja, tenham utilizado por toda a vida a água daquela localidade. N esta etapa, houve também o cuidado de tentar selecionar $50 \%$ de escolares do sexo masculino e $50 \%$ do sexo feminino. Dessa forma, a amostra total contou com 237 escolares assim divididos: 96 de São J oão de Petrópolis (área não fluoretada), 114 de São Roque do Canaã (fluoretação artificial com concentração ideal deflúor) e 27 de Serra de Cima (fluoretação natural com alta concentração de flúor). Tais áreas são localizadas no interior do Estado do Espírito Santo.

Os responsáveis por esses alunos receberam informações por escrito sobre os objetivos do estudo, seus riscos e benefícios, bem como sobre o caráter voluntário da participação de cada criança. Depois de obtida a assinatura no Termo de Consentimento Livre e Esclarecido, iniciou-se a pesquisa.

\section{Análise da água}

Com a finalidade de registro inicial, foi feita uma única análise do teor de fluoreto da água de abastecimento de cada local idade envolvida pelo Setor de Bromatologia do Laboratório Central da Secretaria Estadual de Saúde do Espírito Santo (Lacen), utilizando a técnica do eletrodo seletivo para o íon flúor preconizada por Grøn et al. ${ }^{15}$. A concentração de fluoreto foi medida em três diferentes amostras de cada local: uma amostra coletada pela manhã, uma à tarde e uma à noite. Em São João de Petrópolis, foi confirmada a ausência de fluoreto na água, sendo registrado o valor de $<0,2$ ppmF. Em São Roque do Canaã, os valores encontrados variaram dentro do pa- 
drão estabelecido por Galagan eVermillion ${ }^{16}$, para a fluoretação das águas de abastecimento público de acordo com a temperatura local (0,6 a 1,0 ppmF). Na localidade de Serra de Cima, foram observadas grandes oscilações no teor de flúor natural nos poços (0,4 a 7,1 ppmF).

Para a análise do teor de flúor, foi utilizado o eletrodo específico para o íon flúor Orion 9609 BN \& O rion Research, EUA). 0 equipamento utilizado foi um fluorímetro $\mathrm{pH} / \mathrm{I}$ on 450/M ®(Analyser - Indústria Brasileira). Para o preparo da solução, foram utilizados recipientes de plástico (Plastimed, Brasil) e pi petas descartáveis (Kacil, Brasil). Entre as medições, os eletrodos foram enxaguados com água deionizada e secos com papel toalha (Kitchen, Brasil). Para a calibração do eletrodo, foram preparadas curvas de calibração de 0,250 a $2 \mu \mathrm{g} / \mathrm{ml}$, de acordo com o teor defluoreto. A concentração defluoreto nas amostras foi detectada pela comparação com a curva. Para evitar interferência de outros íons (ferro, cálcio, alumínio etc.), foi misturada à amostra uma solução de $2 \mathrm{ml}$ deTissab II $®($ Orion, EUA).

O Tissab II ®mantém estáveis os íns, eleva o valor do $\mathrm{pH}$ e libera íons flúor que estejam ligados aos íons metálicos. Durante a medição, a amostra líquida foi misturada à temperatura ambiente de $25^{\circ} \mathrm{C}$, com um agitador magnético. A pós a solução final ter-se estabilizado, pôde-se proceder à leitura diretamente no "display" do aparelho em mvolts. A seguir, os valores foram transferidos para ppm por uma fórmula do programa Excel for Windows ${ }^{\circledR}$. Ao início de cada dia de análise, foram preparadas novas curvas e 0 eletrodo foi recalibrado após cerca de 20 medições. Dessa maneira, pôde-se testar com segurança se a capacidade de reprodução dos resultados se situava a $+-2 \%$.

Durante toda a coleta dos dados foi realizada uma análise minuciosa do teor de flúor da água utilizada em cada localidadeenvolvida, totalizando 96 amostras.

\section{Aplicação de questionário}

e realização de exame clínico

Primeiramentefoi perguntado aos pais a respeito da data elocal de nascimento, e da realização de bochechos fluoretados e aplicação tópica de flúor. No exame clínico, realizado em toda a amostra por uma única examinadora devidamente calibrada (Kappa > 0,896), avaliou-se: 0 número de dentes cariados, perdidos e obturados pelo índice CPOD de Klein e Palmer ${ }^{17}$ e a prevalência de fluorose dentária de acordo com
0 índice TSIF de H orowitz et al. ${ }^{18}$, conforme os critérios descritos a seguir: escore 0 - Esmaltesem evidências de fluorose; escore 1 - Esmalte apresentando evidências de fluorose, isto é, áreas de cor branca em menos de 1/3 da superfícievisível. Essa categoria inclui fluorose restrita apenas às bordas incisais dos dentes anteriores e às pontas de cúspides dos dentes posteriores, "cobertura de neve"; escore 2 - Esmalte com áreas brancas de fluorose entre 1/3 e 2/3 da superfície visível; escore 3 - Esmalte com áreas brancas de fluorose em mais de 2/3 da superfície visível; escore 4 Esmalte apresentando manchas, junto com algum dos níveis de fluorose descrito. Mancha é definida como uma área de descoloração que pode variar de marrom claro até muito escuro; escore 5 - Esmalte com depressões discretas, sem a presença demanchas. Corrosão édefinida como um defeito físico na superfície do esmalte, com assoalho rugoso rodeado por paredes de esmalte íntegro. A área corroída é geralmente corada ou de cor diferente do esmalte vizinho; escore 6 Esmalte com depressões discretas em áreas manchadas; escore 7 - Esmalte com pontos de depressão se unindo. Grande área do esmalte pode estar ausente e a anatomia do dente pode estar alterada. Geralmente, encontra-se a presença de mancha marrom escuro.

Os exames foram realizados em cadeiras escolares dispostas nos pátios das escolas, com luz natural e artificial (lanternas portáteis com pilhas alcalinas), utilizando-se sonda exploradora e espelho bucal (Duflex, Brasil). 0 exame foi realizado em campo seco, obtido com o uso de secador de cabelos portátil (Arno, Brasil), na temperatura "frio" e/ou compressas estéreis de gaze (Cremer, Brasil). Alguns escolares da localidadedeSerra de Cima foram examinados nas mesmas condições, porém, na própriaresidência. A póso exame clínico, os escolares receberam um parecer sobre o estado de saúde bucal, informando-os sobre a necessidade de al gum tipo de tratamento.

\section{Análise estatística}

Os dados coletados foram transcritos para o programa Excel for Windows ${ }^{\circledR}$ analisados posteriormente no programa SPSS for W indows ${ }^{\circledR}$.

Para as variáveis qualitativas (realização de bochechos fluoretados e aplicação tópica de flúor) foi elaborada uma tabela de freqüência absoluta e percentual, e foram calculados os valores do teste de hipótese qui-quadrado ou do exato de Fisher (o mais apropriado) e os seus respectivos $p$-valores, com 0 objetivo de deter- 
minar associações estatisticamente significantes entre essa variável e a localidade.

Para as variáveis quantitativas (índiceCPOD, índice de fluorose média, concentração do íon flúor na água de abastecimento), foram calculados o desvio padrão, a média e os valores mínimo e máximo.

Realizou-se o teste de Levene para verificar a homogeneidade das variâncias, pressuposto básico para a utilização do método AN OVA que tem como objetivo testar diferenças globais de médias entre os três grupos (localidades estudadas). Para as variáveis com variâncias homogê neas, utilizamos o teste de média AN OVA e 0 teste a posteriori de Duncan, que determinaram as diferenças específicas entre os grupos. Para as variáveis com variâncias diferentes, utilizamos 0 teste a posteriori de Dunnett.

\section{Resultados}

A Tabela 1 mostra os resultados da análise do teor de flúor da água em vários locais de cada localidade durante 3 meses. Em São João, a totalidade de 12 pontos de coleta representam, respectivamente, durante 3 meses, a escola, a bica da praça, a estação de tratamento deágua e uma torneira na rua. Em São Roque do Canaã, a totalidade de 9 pontos de coleta representam respectivamente, durante 3 meses, a escola, o posto de gasolina e uma torneira na rua. Em Serra de Cima, a totalidade de 75 pontos de coleta repre sentam respectivamente, durante 3 meses, os 25 poços artesianos inseridos na pesquisa. Apresentatambém o resultado do testedehipóteseANOVA para a variável concentração de flúor na água, mostrando um resultado estatisticamente significante entre as médias dos três grupos. 0 teste de Dunnett mostrou que os três grupos são diferentes dois a dois ao nível de $5 \%$ (São J oão x São Roque; São João x Serra de Cima; São Roque x Serra de Cima).
A Tabela 2 apresenta os valores das variáveis bochechos fluoretados eaplicação tópica deflúor (ATF) e o resultado do teste do $\chi^{2}$.

No item bochechos fluoretados, o teste do $\chi^{2}$ apresentou um p-valor não significante, ou seja, a grande maioria dos escolares, independente da localidade, não havia realizado o bochecho.

No item ATF, o teste do $\chi^{2}$ apresentou um $p$ valor significante, ou seja, a grande maioria dos escolares de São João de Petropólis (97,9\%) já haviam recebido ATF, ao contrário de $73 \%$ de São Roque do Canaã e 59\% em Serra de Cima.

A Tabela 3 agrupa os val ores da variável CPOD e o resultado do teste de hipótese ANOVA, que apresentou um resultado estatisticamente significante entre as médias dos três grupos. 0 teste de Dunnett mostrou que não existe diferença estatística entre o índice CPOD de Serra de Cimae de São João de Petrópolis, mas ambos são diferentes de São Roque do Canaã, que possui o menor CPOD.

A Tabela 4 agrupa os valores da variável fluorose média e o resultado do teste de hipótese ANOVA, que apresentou um resultado estatisticamentesignificanteentreas médias dos trêsgrupos. 0 teste de Dunnett mostrou que os três grupos são diferentes doisa dois ao nível de $5 \%$ (São João x São Roque; São J oão x Serra de Cima; São Roque $x$ Serra de Cima).

O Gráfico 1 apresenta os percentuais de dentes encontrados em relação aos escores de fluorose. N ota-sea maior freqüência de escore 0 em São João dePetrópolis, que decresce atéo escore 3. Em São Roque do Canaã, há maior concentração de dentes no escore 1, com presença, entretanto, em todos os níveis. Em Serra de Cima, não existem dentes no escore 0 , mas sim em todos os escores, a partir do 1, com predominância do 2 .

A Tabela 5 apresenta a relação da presença ou não de cárie e a presença ou não de fluorose nos escolares das localidades de São João de Petrópolis, São Roque do Canaã e Serra de Cima e o resultado do teste de Fisher.

Tabela 1. Estatística descritiva da concentração de fluoretos na água (em ppm) de cada localidade, com as respectivas médias, desvio padrão, valor mínimo, valor máximo e resultado do teste ANOVA.

\begin{tabular}{clrcrrr}
\hline Variável & \multicolumn{1}{c}{ Grupo } & N & M édia & D P & Mínimo & Máximo \\
\hline Flúor na água & São João & 12 & 0,12 & 0,03 & 0,08 & 0,18 \\
& São Roque & 9 & 0,81 & 0,09 & 0,7 & 1,02 \\
& Serra de Cima & 75 & 2,54 & 1,93 & 0,4 & 7,6 \\
\hline
\end{tabular}

ANOVA: $F=12,835 ; p=0,000$. 
Tabela 2. Distribuição da frequência absoluta, percentual e resultado do teste $\chi^{2}$ dos escolares de cada localidade quanto à realização de bochechos fluoretados e aplicação tópica de flúor.

\begin{tabular}{|c|c|c|c|c|c|c|c|}
\hline \multirow[b]{2}{*}{ Variável } & \multirow[b]{2}{*}{ Categoria } & \multicolumn{4}{|c|}{ Grupo } & \multirow[b]{2}{*}{$\chi^{2}$} & \multirow[b]{2}{*}{$P$} \\
\hline & & São João & São Roque & Serra de Cima & Total & & \\
\hline \multirow[t]{6}{*}{ Bochecho } & Não & 91 & 109 & 26 & 226 & 0,142 & 0,932 \\
\hline & $\%$ & $94,79 \%$ & $95,61 \%$ & $96,30 \%$ & $95,36 \%$ & & \\
\hline & Sim & 5 & 5 & 1 & 11 & & \\
\hline & $\%$ & $5,21 \%$ & $4,39 \%$ & $3,70 \%$ & $4,64 \%$ & & \\
\hline & Total & 96 & 114 & 27 & 237 & & \\
\hline & & $100 \%$ & $100 \%$ & $100 \%$ & $100 \%$ & & \\
\hline \multirow[t]{6}{*}{ Tópica } & Não & 2 & 30 & 11 & 43 & 37,123 & 0,000 \\
\hline & $\%$ & $2,08 \%$ & $26,32 \%$ & $40,74 \%$ & $18,14 \%$ & & \\
\hline & Sim & 94 & 84 & 16 & 194 & & \\
\hline & $\%$ & $97,92 \%$ & $73,68 \%$ & $59,26 \%$ & $81,86 \%$ & & \\
\hline & Total & 96 & 114 & 27 & 237 & & \\
\hline & & $100 \%$ & $100 \%$ & $100 \%$ & $100 \%$ & & \\
\hline
\end{tabular}

Tabela 3. Estatística descritiva do índice CPOD dos escolares de cada localidade com as respectivas médias, desvio padrão, valor mínimo, valor máximo e resultado de teste ANOVA.

\begin{tabular}{clrcccc}
\hline Variável & \multicolumn{1}{c}{ Grupo } & N & Média & DP & Mínimo & Máximo \\
\hline CPOD & São João & 96 & 5,32 & 3,49 & 0,00 & 13,00 \\
& São Roque & 114 & 1,88 & 2,22 & 0,00 & 10,00 \\
& Serra de Cima & 27 & 3,96 & 2,38 & 0,00 & 10,00 \\
\hline
\end{tabular}

AN OVA: $F=39,225 ; p=0,000$.

Tabela 4. Estatística descritiva do índice de fluorose média dos escolares de cada localidade com as respectivas médias, desvio padrão, valor mínimo, valor máximo e resultado do teste ANOVA.

\begin{tabular}{clrcccc}
\hline Variável & \multicolumn{1}{c}{ Grupo } & N & Média & DP & Mínimo & Máximo \\
\hline Fluorose média & São João & 96 & 0,12 & 0,31 & 0,00 & 1,33 \\
& São Roque & 114 & 1,42 & 0,92 & 0,00 & 4,86 \\
& Serra de Cima & 27 & 3,02 & 1,27 & 1,00 & 5,50 \\
\hline
\end{tabular}

ANOVA: $F=162,596 ; p=0,000$.

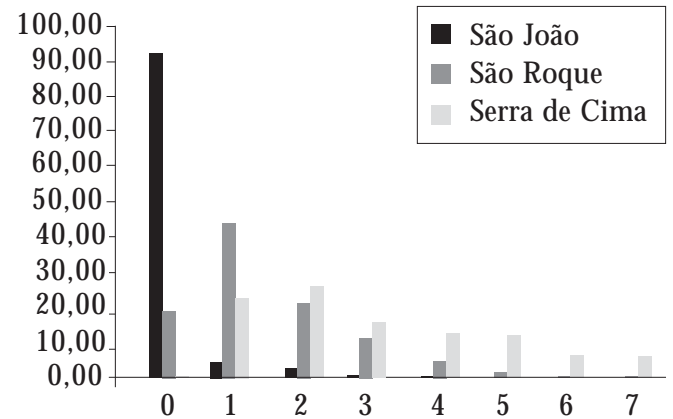

Gráfico 1. Representação gráfica do percentual de dentes em cada escore de fluorose em cada localidade.

\section{Discussão}

A fluoretação das águas de abastecimento público é considerada o método preventivo à cárie dentária de mais ampla distribuição, maior equidade, adesão, melhor custo, efetividade e segurança ${ }^{19}$. Ė sabido, entretanto, queseela não ocorrer corretamente, e dentro dos padrões exigidos, pode causar fluorose em indivíduos que ingerem água de abastecimento público na época de formação dentária.

Muitos autores concordam que a prevalência defluorose dental é maior em área fluoretada do que em área não fluoretada, fato constatado no presente estudo. No entanto, como afirmam 
Tabela 5. Frequência absoluta da presença ou não de cárie e de fluorose conjuntamente em escolares de São João de Petrópolis, São Roque do Canaã e Serra de Cima.

\begin{tabular}{|c|c|c|c|c|c|c|c|c|c|}
\hline & \multicolumn{9}{|c|}{ Fluorose } \\
\hline & \multicolumn{3}{|c|}{ São J oão de Petrópolis } & \multicolumn{3}{|c|}{ São Roque do Canaã } & \multicolumn{3}{|c|}{ Serra de Cima } \\
\hline & Não & Sim & Total & N ão & Sim & Total & $\mathrm{N}$ ão & Sim & Total \\
\hline \multicolumn{10}{|l|}{ Cárie } \\
\hline Não & 5 & 1 & 6 & 3 & 40 & 43 & - & 1 & 1 \\
\hline Sim & 76 & 14 & 90 & 4 & 67 & 71 & - & 26 & 26 \\
\hline Total & 81 & 15 & 96 & 7 & 107 & 114 & - & 27 & 27 \\
\hline
\end{tabular}

Fisher; $p=1,000$.

Cury e Tabchoury ${ }^{20}$, a diferença entre essas áreas tem sofrido uma notável redução com o passar do tempo, e a contribuição da fluoretação das águas, sozinha, quando em teores ideais, sobre o aparecimento da fluorose, é quase impossível, devido à existência de outras fontes de fluoreto.

A condição de saúde bucal dos moradores da localidade com fluoretação natural com alta concentração (Serra de Cima, município de Nova Venécia) vem chamando a atenção da própria população e de gestores de saúde locais há bastante tempo. $\mathrm{Na}$ unidade de saúde próxima ao local existem registros de manchado nos dentes da população oriunda da zona rural desde o início da década de 80. Tais manchados foram descritos pelos dentistas como descalcificações extensas sem a presença de cárie. A pesar denenhuma pesquisa ter sido realizada no local, na década de 80, para quantificar a concentração de fluoretos na água ou mesmo a fonte de contaminação, devido ao isolamento da região eà precariedade do serviço de saúde local, tais registros são fortes indicativos de fluorose dentária. Tal fato também foi confirmado pelos pesquisadores, que observaram fluorose em idosos que nasceram e sempre viveram no local, mesmo não sendo esse, o objeto da pesquisa.

A motivação para inserir a localidade de Serra de Cima no estudo partiu dos diversos convites feitos pela coordenadora de saúde bucal da época, que procurou a Universidade para informar a situação e buscar parcerias para enfrentar o problema.

0 município de São Roque do Canaã possui água de abastecimento fluoretada desde 1983, de acordo com dados da Secretaria Estadual deSaúde do Espírito Santo, enquanto que a localidade São João dePetrópolis, município deSantaTeresa, nunca recebeu fluoretos na água de abastecimento ${ }^{21}$.
No levantamento epidemiológico das condições de saúde bucal da população brasileira - SB Brasil $2003^{22}$ - foi observado que as regiões que apresentaram maior cobertura defluoretação da água, região Sul ( $88 \%$ ) e Sudeste (66\%), foi observada maior prevalência de fluorose dentaria em jovens de 12 anos, 10,75\% e $13,45 \%$ respectivamente.

Do mesmo modo, Khan et al. ${ }^{23}$ realizaram uma revisão sistemática de 55 artigos, com a finalidade de determinar a tendência da prevalência de fluorose em regiões com água fluoretada com as concentrações menores que $0,3 p p m$, entre 0,3 e 0,7 ppm e entre 0,7 e 1,4ppm de flúor, nos anos de 1980 a 2000 . A prevalência defluorose para as três categorias de concentração foi $16,7 \%, 27,4 \%$ e $32,2 \%$, respectivamente.

Os resultados de fluorose média, neste estudo, foram estatisticamente significantes nos três pontos analisados, isto é, a prevalência foi baixa na área sem fluoretação (São João de Petrópolis) e aumentos substanciais ocorreram na área com concentração ideal de fluoretos (São Roque do Canaã), sendo bem mais pronunciada em Serra de Cima, concordando com os achados de M ontero et al. ${ }^{24}$, Pontigo-Loyola et al. ${ }^{25}$, AlmerichSilla et al. ${ }^{26}$.

Foram encontrados casos isolados de fluorose em São J oão de Petrópolis, concordando com Frazolin et al. ${ }^{27}$ que encontrou presença de fluorose em áreas sem fluoretação. Essa situação talvez ocorra em função do uso de bochechos fluoretados e aplicação tópica defluoretos, que este estudo comprovou ter sido maior nessa localidade; ou mesmo pela disseminação do creme dental fluoretado, ou deprodutos deconsumo produzidos em áreas fluoretadas, o que se denomina efeito "halo".

Desta maneira, o íon flúor pode ser encontrado naturalmente em vegetais, carnes, peixes, 
leite, no solo, no ar, e ainda em cremes dentais, fios dentais, medicamentos, vitaminas, aplicações tópicas e, principalmente, na água. Por meio do efeito "halo", o consumo de fluoretos se tornou imperceptível e constante mesmo em locais sem fluoretação das águas de abastecimento.

No Brasil, a partir de 1988, houve uma disse minação de cremes dentais fluoretados, mediante portaria no 22 , do M inistério da Saúde ${ }^{28}$ que estabeleceu um limite mínimo de 600 ppmF para um creme dental ser considerado fluoretado. $\mathrm{Na}$ atualidade, a oferta de cremes dentais fluoretados no Brasil corresponde a mais de $98 \%$, sendo o consumo de cremes dentais infantis, com forte apelo de cor e sabor, um perigo para o surgimento da fluorose, quando sua utilização não é supervisionada pelos pais ou responsáveis, tendo em vista a concentração de fluoretos (entre 1000 e 1500 ppmF) e a ingestão pela criança ${ }^{29}$.

Assim, mesmo na localidade São João de Pe trópolis, sem fluoreto na água de consumo, fica difícil medir a real exposição dos escolares ao flúor em função da presença de bochecho com flúor esporádico nas escolas e da aplicação tópica de flúor, bem como o provável uso de creme dental fluoretado.

Neste estudo, os escolares de São João de Petrópolis haviam recebido mais aplicações tópicas de flúor em relação aos de São Roque do Canaã e de Serra de Cima, refletindo talvez uma política de saúde em função da ausência da fluoretação das águas nesse local. Não foram encontrados, na literatura, trabalhos que avaliam a exposição a bochechos com soluções fluoretadas eaplicação tópica em escolares residentes em locais com diferentes concentrações de fluoreto na água.

A fluorose dentária, como foi verificada nesta pesquisa, também pode ser conseqüência da ocorrência natural de fluoretos em alta concentração nas águas de poços ou nascentes ${ }^{11,26}$. Porém, existem algumas diferenças fundamentais que merecem ser destacadas: os países do chamado grupo de economia de mercado estabelecida (EME) ou da antiga classificação políticoeconômica de primeiro mundo possuem políticas públicas desaúde efetivas a ponto de detectar focos de fluoreto natural em excesso na água e inutilizá-los para uso humano, oferecendo alternativas para consumo. Tal situação, entretanto, não é observada no Brasil, onde muitas vezes a água com excesso natural de fluoretos é a única alternativa de uso para a referida comunidade, sendo muito difícil edispendioso encontrar uma opção para sua substituição.
A prevalência de cárie dentária vem sendo estudada em nível nacional einternacional há muitas décadas. Estudos Iongitudinais procuram monitorar o declínio ou incremento dessa doença, mediante modificações que ocorrem na sociedade estudada. Essas modificações podem relacionar-se com a introdução ou a remoção de práticas de promoção de saúde ou até mesmo com modificações dietéticas ocorridas ao longo do tempo.

0 presente estudo apresenta resultados estatisticamentesignificantes entrea média do índice de cárie dentária (CPOD) das três localidades anal isadas.

A idade dos sujeitos pesquisados variou entre 9 e 16 anos objetivando ampliar a amostra, já que não existia na localidade com fluoretação natural com alta concentração uma população com 12 anos, suficiente para compor a amostra. A idade de 12 anos representa a média da amostra. Comparativamente, para utilizar a idade de 16 anos, de acordo com a OM S (Organização Mundial da Saúde), poderíamos realizar uma proporção, onde aos 16 anos, pela OM S, seria 0 CPO.D em torno de 4 dentes atacados pela doença (aos 12 anos, CPO.D = 3).

São João de Petrópolis apresentou o maior valor médio $(5,32)$, sendo considerado alto pela OM S22. O CPOD médio de Serra de Cima $(3,96)$ é considerado moderado e o CPOD de São Roquedo Canaã $(1,88)$ baixo pela OM S (1997). Vale ressaltar que Serra de Cima apresentou um CPOD mais elevado em função da grande quantidade de restaurações encontradas (componente obturado elevando o índice CPOD), enquanto, em São João de Petrópolis, o componente cariado prevaleceu sobre o obturado. Tal situação encontrada em Serra de Cima pode inclusive estar refletindo certo desconhecimento dos cirurgiões-dentistas acerca das alterações pós-eruptivas causadas pela fluorose, que podem levar à perda de esmalte, com sério comprometimento estético. Assim, a grande quantidade de restaurações não reflete um passado com grande número de lesões de cárie, mas, provavelmente, restaurações feitas por motivos principalmente estéticos e/ou por sensibilidade dentinária por perda de esmalte adjacente.

As inter-relações entre presença ou não de cárie e fluorose conjuntamente de cada localidade analisada foram expressas pelo teste exato de Fisher. A grande maioria dos escolares de São João de Petrópolis não apresentou fluorose e apresentou cárie, seguido de 14 escolares que apresentaram os dois problemas ao mesmo tem- 
po. Em São Roque do Canaã, a situação é diferente. A grande maioria apresentou cárie e fluorose ao mesmo tempo (67), seguido de 40 escolares que apresentaram fluorose e não apresentaram cárie. Em Serra de Cima não foi possível real izar essa inter-relação, em função denão existir escolar na categoria sem fluorose.

Os achados desteestudo em relação ao CPOD vão ao encontro dos de Setwitzet al. ${ }^{30}$, Ely e Pretto $^{3}$, Frazolin et al. ${ }^{27}$ e que também encontraram valores de CPOD menores nas localidades com concentração ideal de fluoretos na água, quando comparados com localidades sem ou com excesso de fluoretos. Esse achado reforça o importante papel da concentração ideal de fluoretos na redução do índice CPOD ${ }^{31,32}$.

A literatura mostra que 0 aumento do teor de fluoretos em água de abastecimento eleva a prevalência defluorose e diminui o índice de cárie até certo ponto, já que com as alterações póseruptivas da fluorose, O CPOD aumenta consideravelmente, principalmenteem função do componente obturado ${ }^{33}$. Os resultados presentes levam à conclusão de que os indicadores epidemiológicos de saúde-doença bucal são influenciados pela presença de fluoretos na água de consumo e que a presença de altas concentrações de fluoretos, seja por ocorrência natural, como em Serra de Cima, ou artificialmente adicionados à água ou a outros produtos submetem a população à fluorose dentária, que se constitui em um problema de saúde coletiva que necessita ser melhor trabalhado pelo poder público na área de saúde.

Os estudos que diagnosticam cárie e fluorose dentária em diferentes regiões do Brasil edo mundo deveriam sempre levar em consideração as diferenças no clima, consumo de água, nutrição, padrão de vida, exposição a outras fontes de fluoreto que determinada população está exposta. Tais variáveis geral mente tornam as comparações e generalizações extremamente difíceis. As comparações também são complexas quando se utilizam índices diferentes de detecção de fluorose.

Segundo dados do levantamento epidemiológico SB Brasil22, cerca de $46 \%$ dos municípios do Brasil recebem água artificialmente fluoretada. Portanto, os órgãos públicos deveriam apre sentar estratégias tanto para avaliar constantementeo teor defluoreto dessas localidades quanto para estimar a exposição de fluoreto natural de fontes ou de poços de água, medindo criteriosamente a dosagem adequada eavaliando os riscos e os benefícios. 0 que, infelizmente, ocorre no Brasil é que muitas autoridades vêm projetando sistemas públicos de abastecimento de água sem saber que o fluoreto é um componente natural da água, portanto estudos preliminares deveriam ser realizados. Apesar disso, também não é fato desconhecido que uma parcela da população brasileira não tem acesso à água tratada, 0 que aumenta em muito a prevalência de doenças de veiculação hídrica.

A Portaria no. 51834, de 24 de março de 2004, que apresenta os procedimentos e responsabilidades relativos ao controle e vigilância da qualidade de água para consumo humano, estabeleceu que a concentração das águas fluoretadas artificialmente não deve exceder 1,5 mgF/L, mas a concentração adequada para cada região do país deve ser calculada com base na temperatura média anual do local ${ }^{16}$.

De acordo com Tomita et al. ${ }^{35}$, a ocorrência de fluorose em escolares, mesmo em níveis muito leve a moderado, surge como conseqüência de ações deficientes no campo da vigilância à saúde. A prevalência de fluorose média em São Roque do Canaã indica uma grande disponibilidade de produtos fluoretados aos escolares. A existência depontos discrepantes nessa local idade com concentração ideal de fluoretos mostra a ingestão em excesso de fluoretos em tenra idade.

A concentração de fluoretos ideal para a localidade deSerra de Cima éde 0,7 ppm, considerando a média de suas temperaturas máximas diárias. Sendo assim, os moradores dessa localidade estão consumindo água poluída por elevadosteores defluoreto. A partir de 1985, a própria população começou a notar alterações em seus dentes, a exemplo do queaconteceu com a população de Cocal, SC ${ }^{36}$. Alarmados com o problema, alguns moradores se organizaram em busca deesclarecimentos esoluções. Se possível, a solução ideal seria a substituição imediata dos poços que apresentam elevada concentração de fluoreto por outros poços sem fluoreto natural ou com concentração ideal do íon, ou mesmo a instalação de algum método de desfluoretação ativa, como os citados por Møller ${ }^{1}$, sempre observando, nesses casos, a relação custo/benefício. Vale ressaltar, numa inferêncialógica, queanimais para consumo humano que se utilizam dessa água também passam a acumular fluoretos em seu organismo, assim como vegetais cultivados em áreas regadas com água com alto teor de fluoreto também apresentam esse componente em sua constituição, contribuindo para reforçar o acréscimo de fluoretos no corpo humano.

De acordo com Sinaij7, uma questão de saúde éconsiderada como problema para a saúde públi- 
ca quando constitui causa comum de morbidade ou mortalidade, quando existem métodos eficazes de preven ção e controle dessa doença, e tais métodos não estão sendo utilizados demodo adequado pela comunidade. Observando os critérios estabelecidos por Sinai, a fluorose dentária deve ser considerada um problema para a saúde coletiva por contemplar a tríade proposta. Com relação a ser um problema prioritário, deve-se localizar a população em questão no tempo e no espaço. Até a década de 50, as doen ças infecto-contagiosas eram as principais causa mortis no Brasil. Hoje são as doenças cardiovasculares que ocupam essa posição. Deigual forma, na Odontologia, o queé problema no Acrepodenão ser no Rio Grandedo Sul. Assim, em nosso estudo, a fluorose dentária é prioritária para a população de Serra de Cima, por contemplar os critérios de hierarquização de problemas. Entretanto, entendemos que a análise da água para a verificação de sua composição, antes de seu tratamento de potabilidade seja uma questão prioritária em qualquer região do país, pela possibilidade da disseminação de doenças de veiculação hídrica.

Por princípio, alguns indivíduos não aceitam a fluorose dentária, independente do nível, por se tratar de uma alteração que pode ser evitada ${ }^{38}$. Outros ponderam que deve ser levado sempre em consideração o risco/ben efício. Se a redução decárie naquele local superar, em termos desaúde pública, os níveis de fluorose dental, a ocorrência de fluorose será aceitável${ }^{29}$.

\section{Colaboradores}

U V M edeiros orientou o delineamento da pesquisa e a redação do artigo. $\mathrm{R} B$ Carvalho realizou os exames, as análises laboratoriais e a análise dos dados e orientou a redação do artigo. $\mathrm{K}$ T Santos eA C Pacheco Filho auxiliaram na coleta e tabulação dos dados e redigi ram 0 artigo.
Do ponto devista sociopsicológico, podemos dividir a percepção da comunidade em necessidades sentidas e em não sentidas. Necessidade sentida significa que a comunidade percebe 0 problema e o relata, como em Serra de Cima; ea necessidade não sentida mostra a existência do problema, mas a comunidade não o relata, pois não o percebe.

M uitas vezes, o cirurgião-dentista diagnostica a fluorose dental nas crianças, porém as mães não relatam nada de anormal nos dentes de seus filhos, isto é, não há percepção do nível de fluorose. Quando ocorre a fluorose, esta é vista de forma diferente entre a população e os profissionais da O dontologia, o que refletecircunstâncias individuais, bem como valores culturais que devem ser avaliados ${ }^{39}$

Assim sendo, algumas perguntas devem ser feitas: fluoroseéapenas um fator estético? Quantos profissionais conhecem e sabem diagnosticar corretamente a fluorose dentária? Quando a fluoroseéinconvenientee quando ela édesprezível, proporcionando ótimos benefícios na prevenção da cárie e poucos efeitos colaterais?

Tais questões encontram eco quando analisamos seriamente as possíveis relações existentes entreo índice de cáriee a presença e/ou severidade defluorose, nos levando à conclusão de que o poder público necessita ampliar suas políticas de saúde, principalmente no que concerne à saúde bucal e à interação desta com a saúde geral, representada pelo consumo excessivo defluoretos.

\section{Referências}

1. Möller IJ. Fluorides and dental fluorosis. Int Dent 1982; 32:135-147.

2. Murray JJ. Appropriate use of fluoride for human health. Genebra: World health Organization; 1986.

3. Ely HC, Pretto SM. Fluorose e cárie dentária: estudo epidemiológico em cidades do Rio Grande do Sul com diferentes níveis de flúor nas águas de abastecimento. Rev Odonto Ciência 2000; 31:143-173.

4. Moysés SJ, Moysés ST, Allegretti ACV, Argenta M, Werneck R. Fluorose dental: ficção epidemiological? Rev Panam Salud Publica 2002; 15:339-346.

5. Forte FDS, Santos NB, M oimaz SAS, Saliba, NA. Bases científicas para um correto diagnóstico de fluorose dentária. J Bras Clin Odontol Int 2002; 6(36):494-496.

6. Khan A, Moola MH, Cleaton-Jones P. Global trends in dental fluorosis from 1980 to 2000: a systematic review. SADJ 2005; 60(10):418-21.

7. Fejerskov O, Baelum V, Manji F, Moller JJ. Fluorose dentária: um manual para profissionais de saúde. São Paulo: Santos; 1994. 
8. Uchoa HW, Saliba NA. Prevalência de fluorose na cidade de Pereira Barreto. Bol Serv O dont Sanit 1970; 6:11-16.

9. Ando T. Estudo comparativo da prevalência de cárie, em dentes permanentes de escolares residentes em regiões com alto e baixo teor de flúor. Rev Fac Odontol Univ São Paulo 1975; 13:261-266.

10. Alcaide $A L$, Veronezi $O$ Prevalência de fluorose dental na cidade de Icem. Rev Assoc Paul Cir Dent 1979; 33:90-95.

11. Capella LF, Carcereri DL, Paiva SM, Rosso RA, Paixão RF, Saltori, EK. Ocorrência de fluorose dentária endêmica. RGO 1989; 37(5):371-375.

12. Sampaio FC. Prevalência de cárie e fluorose dental em cidades com fluoretação natural no estado da Paraíba. [dissertação]. Rio de Janeiro: Faculdade de Odontologia da Universidade Federal Fluminense; 1992.

13. Pereira AC, Moreira BW. Analysis of three dental fluorosis indexes used in epidemiologic trials. Braz Dent J 1999; 10(1):29-37.

14. Cangussu MCT, Narvai PC, Fernandez RC, Djehizian V. A fluorose dentária no Brasil: uma revisão crítica. Cad Saude Publica 2002; 18(1):7-15.

15. Grøn P, McCann HG, Brudevold F. The direct determination of fluoride in human saliva by a fluoride electrode. Archs Oral Biol 1968; 13:203-213.

16. Galagan DJ, Vermillion JR. Determining optimum fluoride concentrations. Public Health Rep 1957; 72:491-493.

17. Klein H, Palmer CE. Studies on dental caries. X. A procedure for the recording and statistical and processing of dental examination findings. J Dent Res 1940; 19:243-256.

18. Horowitz HS, Driscoll WS, Meyers RJ, Heifetz SB, Kingman $A$. A new method for assessing the prevalence of dental fluorosis: the Tooth Surface Index of Fluorosis. J Am Dent Assoc 1984; 109(1):37-41.

19. Yeung CA. A systematic review of the efficacy and safety of fluoridation. Evid Based Dent 2008; 9:39-43.

20. Cury JA, Tabchoury CPM. Determination of appropriate exposure to fluoride in non-eme countries in the future. J Appl Oral Sci 2003; 11(2):83-95.

21. Secretaria de Estado da Saúde do Espírito Santo. Informações sobre condição de fluoretação das águas de abastecimento público dos municípios do Estado do Espírito Santo. Vitória: Secretaria de Estado da Saúde do Espírito Santo, 2001.

22. Brasil, M inistério da Saúde. Projeto SB Brasil 2003 Condições de saúde bucal da população brasileira 20022003 - Resultados Principais. Brasília: DF; 2004.

23. Khan A, Moola M H, Cleaton-Jones P. Global trends in dental fluorosis from 1980 to 2000: a systematic review. SADJ 2005; 60(10):418-421.

24. Montero M, Rojas-Sanchez F, Socorro M, Torres J, Acevedo AM. Dental caries and fluorosis in children consuming water with different fluoride concentrations in Maiquetia, Vargas State, Venezuela. Invest Clin 2007; 48(1):5-19

25. Pontigo-Loyola AP, Islas- $M$ árquez $A$, Loyola-Rodríguez JP, M aupome G, M arquez-Corona M L, $M$ edina-Solis CE. Dental fluorosis in 12 - and 15 year-olds at high altitudes in above-optimal fluoridated communities in M exico. J Public Health Dent 2008; 68(3):163-166.
26. Almerich-Silla JM, M ontiel-Company JM, Ruiz$M$ iravet $A$. Caries and dental fluorosis in a western Saharan population of refugee children. Eur J Oral Sci 2008; 116(6):512-517.

27. Frazolin SOB, Gonçalves A, Pandovani CR, Francischone LA, M arta SN. Epidemiologia da fluorose da cárie dentária de acordo com diferentes tipos de fontes de abastecimento de água. Cienc Saude Colet 2010; 15(Supl. 1):1841-1847.

28. Brasil. M inistério da Saúde. Portaria no 22/SNVS de dezembro de 1989: define normas para registro e controle de enxaguatórios bucais com flúor para uso diário e de dentifrícios com flúor. Diário O ficial da União 1989; 22 dez.

29. Lima YBO, Cury JA. Ingestão de flúor por crianças pela água e por dentifrícios. Rev Saude Publica 2001; 35(6):576-581.

30. Setwitz HR, Nowjack-Raymer RE, Kingman A, Driscoll WS. Prevalence of dental caries and dental fluorosis in areas with optimal and above optimal water fluoride concentrations: a 10-year follow-up survey. J Public Health Dent 1995; 55(2):85-93.

31. Cunha LF, Tomita NE. Dental fluorosis in Brazil: a systematic review from 1993 to 2004. Cad Saude Publica 2006; 22(9):1809-1816.

32. Ramires I, Buzalaf MAR. A fluoretação da água de abastecimento público e seus benefícios no controle da cárie dentária - cinqüenta anos no Brasil. Cien Saude Colet 2007; 12(4):1057-1065.

33. Louw AJ, Grobler SR. Relationship between drinking water fluoride levels, caries and fluorosis. In: Annals of International Association for Dental Research 2002; $A(276): 2154$.

34. Brasil. M inistério da Saúde. Portaria 518 de 24 de março de 2.004. Estabelece os procedimentos e responsabilidades relativos ao controle e vigilância da qualidade da água para consumo humano e seu padrão de potabilidade. Brasília (DF), Editora do Ministério da Saúde 2004; 25 mar.

35. Tomita NE, Panighel CPMA, Narvai PC, Lopes ES. Implicações da vigilância à saúde sobre a ocorrência de fluorose dental. Rev ABO Nac 1995; 3(5):318323.

36. Paiva SM, Paixão RF, Capella LF, Carcereri DL, Rosso RA, Freitas ARR, Barros Filho MA. A fluorose dentária sob o ponto de vista de uma comunidade atingida. RGO 1993; 41(1):57-58.

37. Chaves M M. Odontologia social. São Paulo: Artes M édicas; 1986.

38. Demos LL, Kazda H, Cicuttini FM, Sinclair MI, Fairley CK. Water fluoridation, osteoporosis, fractures: recent developments. Aust Dent J 2001; 46(2): 80-87.

39. Peres KG, Latorre MRDO, Peres MA, Traebert J, Panizzi M. Impacto da cárie e da fluorose dentária na satisfação com a aparência e com a mastigação de crianças de 12 anos de idade. Cad Saude Publica 2003; 19(1):323-330.

Artigo apresentado em 17/10/2008

Aprovado em 09/04/2009

Versão final apresentada em 28/04/2009 